DOI: 10.14526/2070-4798-2020-15-1-106-114

\title{
The role of the family, school, university, and state in solving the problem of young people physical education
}

\author{
Aleksey P. Popovich*, Aleksandr V. Bezukladnov \\ First Russian President B. N. Yeltsin Ural Federal University \\ Ekaterinburg, Russia \\ ORCID: oooo-ooo3-0149-4885, Alex1957popovich@mail.ru* \\ ORCID: oooo-ooo2-8505-3069, Bezal-59@mail.ru
}

\begin{abstract}
A healthy lifestyle for a modern person is the main guideline and motivation in the process of life, a priority goal and life attitude aimed at preserving health, longevity, successful professional activity and high quality of the individual life. The concept of "quality of the population life" informs about the degree of material satisfaction, spiritual, and social needs of a person. Materials. The article discusses the relationship between the concepts of "healthy lifestyle", "quality of the population life" and the formation of "physiological needs" during systematic physical exercise. Research methods. Analysis and generalization of scientific literature. Results. It is shown in what forms ecosystem disturbance affects human health. The authors consider the problems in the pedagogical process aimed at the formation of a healthy person, and justify the high requirements for the level of physical culture and sports workers professional training. The types of family education are classified. The tasks that need to be solved to improve the level of parents pedagogical culture and criteria for the effectiveness of healthy lifestyle education are formulated. On the example of the research conducted by the Russian Academy of education, many problems in the field of professional and General education are revealed. According to the results of this study, factors that negatively affect the processes of forming a healthy lifestyle of young people are identified. Conclusion. The study shows the importance of physical culture mass occupations role for the preservation of health and prolongation of human life, the conclusion about the necessity of an integrated approach in achieving this goal formation of a harmoniously developed personality.

Keywords: healthy lifestyle, physical culture, quality of life, professional training, education, ecology, negative factors, family education.
\end{abstract}

For citation: Aleksey P. Popovich*, Aleksandr V. Bezukladnov. The role of the family, school, university, and state in solving the problem of young people physical education. Russian Journal of Physical Education and Sport. 2020; 15(1): 87-93. DOI: 10.14526/2070-4798-2020-15-1-106-114

\section{INTRODUCTION}

A healthy lifestyle for a modern person is the main reference point and motivation in the process of life, a priority goal and life attitude aimed at maintaining health, longevity, successful professional activity and high quality of theindividual life. The concept of "quality of the population life" informs about the degree of a person material, spiritual, and social needs satisfaction. Social structures of highly developed countries conduct active educational work among their citizens, aimed at forming a "physiological need" for systematic physical exercise.

The evolutionary processes of society, the development of the economy, industry, and increasing the level of material and technical benefits for a person have a positive effect, along with a different technological side. As a rule, it is the main cause of environmental pollution. This leads to disruption of the ecosystem. It affects human health. According to statistics from the world Health Organization, the main cause of human disease is adverse environmental conditions (85\%). The level of health is indicated as the main criterion for the quality of human life. The environment in all its manifestations can have both a positive and negative impact on it. It exposes the human adaptive and immune systems to additional stress. The human body reacts to any changes in the external environment. The reaction is individual, depending on the following factors: gender, age, health status, physical fitness, professional activity [1].

We draw attention to the problems facing parents, teachers, and the public. They are responsible for the younger generation healthy lifestyle foundations formation, deep knowledge 
of physical culture, and the value potential of this phenomenon. Heredity, family upbringing, society or educational state institutions are the dominant structures in the process of educating the younger generation. All this creates high requirements for the level of physical culture and sports employees professional training. The authors tried to consider the problems aimed at forming a harmoniously developed personality in the pedagogical process.

"Healthy lifestyle" is a way of life that corresponds to genetically determined typological characteristics of a person, specific living conditions aimed at forming, preserving and strengthening health, performing its socio-biological functions. A healthy lifestyle, as a system, consists of three main cultures: nutrition, movement, and emotions [4].

Socialization and formation of the child as a person depend on family education. This is the process of influencing children by parents and other family members in order to achieve the desired results from family education. There are the following types of the individual family education: civil, secular, marginal, elite. It is advisable to add scientific-religious, integral, class and party education to this list.

The type of child's personality is formed by the style of educational activity [5]:

- authoritarian;

- liberal;

- humanistic;

- democratic;

- pragmatic.

The content of education in the family is determined by its orientation in the educational process:

- mental;

- moral;

- physical;

- harmonious.

Parents build their behavior differently in the process of raising children. It is classified as follows [6]:

- strict;

- compromise;

- autonomous;

- promotional;

- situational;

- dependent.

Children are a reflection of the family. Speaking about education, P.F. Lesgaft highlighted the conditions for the formation of a full-fledged child's personality only in an atmosphere of love and mutual respect, without this, the child develops ambition and immorality on the basis of compensatory love for the child, especially from the mother. At the same time, according to the great scientist and teacher, a great role was given to the harmonious development and education of a person by means of physical culture [7].

The education of a healthy person is of the greatest value. It depends on a number of objective and subjective factors. The generally recognized fact of deterioration in the health of modern children and adolescents is associated with a lack of motor activity and a sedentary lifestyle. The rhythm of the twenty-first century, its intensity does not leave time to devote enough time and attention to the physical education of their children. But at the same time, the problem remains the lack of the parents themselves culture. And physical culture is part of the "universal culture". The organization of everyday life, observance of the daily regime, and nutrition of the child do not yet speak about physical education. It is necessary to approach comprehensively, along with the above factors, to master health-saving technologies, knowledge about the optimal combination of motor activity and rest of the child's body, the laws of human adaptive abilities development, taking into account the age periodization. The words A.S. Makarenko remain relevant for parents, educators, and teachers: "And a high demand for yourself, for each step, respect for your family, parental control over each step is the primary and main step in education." Active physical exercise is an integral element of the individual physical education. Parents should act as role models [8].

The family contributes to the formation of a child's lifestyle, skills and abilities, the basics of a healthy lifestyle, and the systematic use of tempering procedures.

One of the problems of raising a healthy lifestyle is to raise the cultural level of parents. Parents bear full legal and moral responsibility for raising a child in the family. It is supported by the laws of any state, as for example, in article 63 of the Russian Federation Constitution on the duties of parents.

Great teachers of the XIX-XX century K.D. Ushinsky, L.N. Tolstoy, P.F. Lesgaft, V.P. Vakhterev, 
P.F. Kapterev emphasized the importance of coordination and interaction of family and school education. When laying the foundations of family education, parents rely on their life experience without having pedagogical knowledge. It makes impossible to consciously influence children in order to correct their behavior.

Teacher P.F. Kapterev noted that the basis of interaction between the family and the school is the development of the child's hereditary abilities and capabilities, including physical, creative, and labor ones.

Representatives of pedology P.P. Blonsky, L.S. Vygotsky, D.B. Elkonin considered it necessary to preserve the unity and continuity of upbringing and education in the family and school in accordance with the theory of individual development on the basis of biological and social unity. The Soviet school of pedagogy and its representatives A.V. Lunacharsky, N. K. Krupskaya, and A. S. Makarenko set the main task of studying the microenvironment around the child and providing advice to the family [9]. Nevertheless, the Soviet school behaved authoritatively regarding the family, paying mainly attention to the military - patriotic education of children, teenagers, and young people, and this continued until the 9o's. N. K. Krupskaya's ideas about high socialization of children and their implementation had a negative impact on the genetic level of generations, manifested in the separation of preschool and primary school age children from the family way of life and traditions.

\section{MATERIALS AND METHODS}

To improve the level of parents pedagogical culture it is necessary to solve the following tasks: - parents ' understanding of the raising children purpose;

- taking into account the individual characteristics and uniqueness of the child;

- matching children's capabilities and parents ' requirements;

- ability to make decisions in a specific pedagogical situation in order to develop the child;

- variety of applied methods and means of education.

The developed models of behavior are instilled in the child by parents on the basis of ethics and rules, cultural traditions. Self-analysis of children occurs after comparing their own actions with known patterns of behavior, usually set by parents. Individual experience and physical environment, as well as culture, nature, and climate have a great influence on a person [10].

One of the fundamental tasks of education in the family is the formation of a daily routine, a regime that is important for children of any age. The family organizes the optimal home mode - motor activity that contributes to the physical development of the child, sleep, rational nutrition, tempering, personal hygiene. Home mode should be based on the daily routine of both preschool and school institutions. According to Amosov, the following conditions are necessary for health [11]:

- exercise;

- optimal nutrition;

- adaptation of the body to the environment;

- a harmonious combination of work and leisure.

The family forms a healthy lifestyle for children and instills the following knowledge, skills and abilities:

- knowledge of the personal hygiene rules, hygiene of premises, clothing, shoes, etc.

- the need to strictly observe the daily routine;

- ability to analyze everyday situations, predict the consequences and find a way out of them;

- ability to interact with the environment, compliance with the rules of safe stay in society and everyday life.

Parents need to know the criteria for the effectiveness of healthy lifestyle education:

- positive dynamics of the child's physical development;

- reduce morbidity;

- formation of the child's ability to build relationships with peers, parents and other people;

- reducing the level of anxiety and aggression.

It is obvious that a positive result can only be achieved if the family and the educational institution work closely together. Since the needs for a healthy lifestyle in a child will be formed only on the basis of common requirements for them from parents and teachers. Only if this condition is met, the child will perceive a careful attitude to his health as an immutable truth, the only correct style of life [12].

We see how a person, engaged in physical culture, changes himself, at the same time influencing, changing the world around him. It is advisable to consider how society affects the 
physical development of a person. We imagine that in the primitive communal system, the physical development of man was extremely necessary for elementary survival in the environment. We will understand the simple postulate that the comprehensive development of man corresponds to his time and epoch. That is, physical culture, its level of development corresponded to the requirements of a particular socio-economic formation - primitive, slave-owning, feudal, capitalist [1].

The material side of society causes the emergence of physical culture as an integral part of human culture. The conditions of human life were such that he was in an atmosphere of confrontation between strength, speed, and dexterity with the world around him and nature. But not only physical culture was in demand, since it is difficult to separate the concept of "physical culture" from culture in General. Humanitarians consider the concept of "culture "as a bridge between the human" bio - structure" and the environment. The concept of "culture" includes philosophy, ideology, morality, art, and many other disciplines of humanitarian orientation. Culture reflects the most complex processes of material and spiritual life of society. It is not given to man by nature, being the result of social and individual creativity of people. The basis of the content of the cultural process is formed by means and methods that develop the physical and intellectual abilities of a person [6].

It is difficult to overestimate the importance of mass physical training for preserving health and prolonging the life of mankind. The costs of civilization have affected the health of modern man. The only way to survive today is to neutralize or minimize the impact of adverse environmental factors:

- hypodynamia;

- excessive high-calorie food;

- nervous overstrain.

The role of the state in managing the development of physical culture and its influence on the education of its citizens is great. That is, the state is still the main customer, which citizen is needed today in the country. But the main" accumulator " and conductor of the educational process is the teacher. The basis of the professional competence the criterion of the effectiveness of its level, is the quality of the lesson it conducts. At the same time, it is necessary to systematically monitor the educational process, program and methodological material in order to make timely adjustments to the studied disciplines, "responding" to the "requests and requirements" of modern youth, society, and the state in this discipline.

\section{RESULTS}

Using the example of a study conducted by the RUDN in 2016, in which the author of the publication participated, many problems in the field of professional and general education and the role that is assigned to state institutions in the formation of a healthy lifestyle for young people are revealed. Among the respondents were about 60 thousand students of various Russian universities.

Based on this data, $80 \%$ of students are not distributed by sports and are engaged in general physical training groups (OFP). This contradicts the requirements of the Federal educational standard. $55.6 \%$ of students rate classes positively. $73 \%$ of students receive explanations and methodological support of the study material, including $22.9 \%$ using modern computer and media technologies, and $24 \%$ using manuals and methodological material. Students attending lectures on physical culture $54.8 \%$.

Additional dance classes, hiking trips, and exercises on simulators are of increased interest among young people - 86\% of the respondents. Medical and practical classes that provide information about the health of $72 \%$, diagnostics of the functional state-in $48 \%$ of students. As a necessity for improving the quality of physical education classes, as well as the criteria for evaluating the teacher's work will be the following factors:

- availability and quality of developed documentation during planning;

- planning and monitoring classes;

- rational distribution of classes ("motor" and "general" density).

- compliance with safety rules and sanitary requirements;

- taking into account individual, age and gender characteristics;

- creative use of health-saving technologies;

- control of knowledge and skills;

- use of modern inventory.

The higher school teacher completes the formation of students ' conscious attitude to a healthy lifestyle by means and methods of physical 
culture:

- improves knowledge, skills and abilities of basic body exercises;

- maximizes motor experience;

- masters the techniques of psych when create a positive emotional background during class.

According to the results of this study, the factors that negatively affect the processes of forming a healthy lifestyle of young people are identified.

Physical improvement is hindered by the following reasons:

- insufficient level of information for young people in the field of fundamental knowledge of anatomy, physiology, morphology, as well as the theory and methods of physical education;

- negative experience of physical education at school or other educational institution;

- conditions for independent studies are not comfortable enough;

- systematic violations and ignorance of the healthy lifestyle basics (work and rest, food, sleep);

- lack of psychological support for independent activities with family and friends;

- temporary illness and ill health;

- lack of inventory, equipment, equipment and other support necessary for systematic physical training.

Solving the above-mentioned problems, increasing thelevel of knowledgein the field of healthsaving technologies, forming internal psychological confidence in the vital need to strengthen one's own health as a basis for happiness, career success, and longevity, all of these together are attributes of modern man and his life.

Physical development of a person is a natural change in anatomical, physiological, and biological structures in the course of an individual's life.

Indicators of a person physical development: - functional capabilities of the body cardiovascular and respiratory systems;

- physique indicators; the level of the physical qualities status;

- functional physiological changes;

- age period of development.

Factors affecting a person's physical development:

- endogenous, these include genetic features that are carriers of hereditary diseases and pathologies that affect the process of growth and development of the individual;
- exogenous (climate indicators, natural, water resources, ecology, area of residence);

- social (food, education, status of the child in the family, medical care).

Physical education in high school is of paramount importance for the study and development of rational and effective use of human motor abilities and capabilities. Directly the object and factor of management is motor activity, training in movements, education of physical qualities, their relationship. Physical education is aimed at morphological and functional improvement of the body, strengthening the health of the body, performing the following functions:

- developmental;

- educational;

- health and hygiene;

- general cultural.

\section{DISCUSSION}

On the example of the Russian Federation, we can consider the mechanisms of state internal policy aimed at preserving and improving the health of its citizens.

The current Concept of long-term socioeconomic development of the Russian Federation until 2020 provides for increasing the level of physical culture development, reducing mortality among the working-age population of the country and stabilizing the demographic situation. Involving children in systematic physical exercise will help improve socio-economic indicators in the country in the near future. In the opposite case, the trend of reducing life expectancy will continue. It will also be accompanied by large financial and economic losses of the state due to the growth of diseases [14]. Almost all aspects of human life are determined by the level of health.

The state has a broad influence on physical culture and sports activities in two main areas:

- creation and development of the legal framework; - financing and investment in this area.

The activities of any state in this area are based on the international legal framework. The main documents in the field of sports are the international Charter of physical education and sports of 1978, adopted in Paris, as well as the European sports Charter of 1992.

The sports Charter was adopted in 1992 by representatives from thirteen European countries. 
Dominating in this law were the rights of citizens about everyone's access to physical education, knowledge acquisition, protection and development of the moral and ethical aspects of sport. It is also pointed out that special care is taken for the environment, both during the construction of sports facilities and during sports events.

Another document that I would like to draw attention to is the European Manifesto "Young people and sport", adopted in may 1995.

The main goal of this Manifesto is to promote a healthy lifestyle among young people and solve the following tasks:

- development of physical, mental and social qualities;

- teaching ethical values of justice;

- mutual respect;

- tolerance;

- promotion of healthy lifestyles [13].

The Manifesto States that family and school play a unique role in promoting healthy lifestyles. As we can see from the Manifesto, the main directions of physical culture activities are humanization and humanitarization of both the process itself and the relationship between teachers and students. When organizing the process and classes in the epicenter is the student, the person's personality and selfrealization, the manifestation of his abilities. The formation and realization of its potential as an individual is possible only in the conditions of a coordinated unity development of its intellectual, spiritual, moral, aesthetic and physical aspects. Humanization educational processes contributes to the development of individual abilities based on a healthy lifestyle.

Analyzing the achievements and problems of modern civilization, the authors of the article note the increasing role of a healthy lifestyle in human life. Humanity in the 21st century has achieved great evolutionary progress in almost all spheres of society life. The development of a person as a person, an individual, takes place on the basis of his socio-biological abilities and needs. The main ones are motivations for self-realization and self-actualization. But it is impossible to achieve your goals in a highly competitive environment without mastering the skills and fundamentals of a healthy lifestyle. Despite the many contradictions that are taking place in the world today, we can distinguish two main problems-the preservation of human health and the environment. Man as a biological structure can not exist in a vacuum, and environmental problems humanity can solve only by combining efforts and aspirations for this. Scientists predict an increase in the average life expectancy of a person to 120 years, and this is real. But it should be taken into account that along with the development of health-saving technologies, the environment is deteriorating at a high rate. This is especially true over the past decade in the tourism industry. It is growing at an annual rate of $2.8 \%$.

In the process of educating a healthy lifestyle, the main role is given to the family. The first example of a healthy lifestyle is taught to their children by their parents. Educational institutions systematize the acquired skills in the field of health preservation and raise the level of the need awareness to preserve and strengthen health as the basis for a successful professional career and longevity. Creating conditions for the organization of the child correct mode, a combination of activities, rest, sleep, and food intake is a direct responsibility of parents.

In the educational institution, children will get the necessary knowledge about the means and methods of physical culture, about harmonious physical development based on their individual abilities. At the University, the educational process should be based on the democratic choice of sports, the maximum implementation of its motivations for the conscious development of physical qualities and abilities, to achieve its life goals based on a healthy lifestyle [14].

\section{CONCLUSION}

The state, at the legislative, regulatory and legal level, creates conditions for systematic training in maintaining a healthy lifestyle for its citizens, while improving the material and technical base of sports halls and stadiums. Provides free access to sports facilities for various social groups and segments of the population, in accordance with signed international documents and Charters. A modern person who leads a healthy lifestyle is a harmoniously developed person. He is capable of a successful career, longevity and creating a basis for a happy future for future generations.

\section{REFERENCES}

1. Vasilyeva Z.I. Istoriya obrazovaniya $i$ 
pedagogicheskoy mysli [History of education and pedagogical thought]. M. 2009: 413 [In Russ.].

2. Fudin N.A., Khadartsev A.A., Orlov

V.A. Mediko-biologicheskiye tekhnologii $v$ fizicheskoy kulture i sporte [Medical and biological technologies in physical culture and sports]. M.: Sport-man. 2018: 320 [In Russ.].

3. Stepanenkova E.Ya. Teoriya I metodika fizicheskogo vospitaniya I razvitiya rebenka [Theory and methods of physical education and child development]. M.: Central Academy. 2001: 368 [In Russ.].

4. Atayev A.K. Roditelyam o fizicheskom vospitanii detey $v$ semye [Parents about physical education of children in the family]. 2013: M.: MGU. 2013: 320 [In Russ.].

5. Kholodov Zh.K., Kuznetsov V.S. Teoriya $i$ metodika fizicheskogo vospitaniya $i$ sporta [Theory and methods of physical education and sports]. M.: Academy. 2013: 480 [In Russ.]

6. Stepanov T.A. Vospitaniye interesa $k$ fizicheskoy kulture u detey s razlichnym urovnem zdorovia [Fostering interest in physical culture in children with different levels of health]. Surgut, SurGPI. 2014: 170 [In Russ.].

7. Barshay V.M. Fizicheskaya kultura $v$ shkole $i$ doma [Physical education at school and at home]. Rostov-n-D.: Feniks. 2011: 256 [In Russ.].

8. Zakharova L.I. Mezhdunarodnoye sportivnoye pravo [International sports law]. M.: Prospekt. 2017: 272 [In Russ.]

9. Alekseev S.V. Pravovye osnovy professional'noj deyatel'nosti $v$ sporte [The legal basis of professional activities in sport]. M. 2013: 517 [In Russ.]

10. Andersen L.B., Riddoch C., Kriemler S., Hills A. Physical activity and cardiovascular risk factors in children. British journal of Sports Medicine. 2011; 45(11): 871-876. DOI: 10.1136/ bjsports-2011-090333.

11. Carson V., Spence J.C. Seasonal variation in physical activity among children and adolescents: A review. Pediatric Exercise Science. 2010; 22: 81-92.

12. Fairclough S.J., Ridgers N.D., Welk G. Correlates of children's moderate and vigorous physical activity during weekdays and weekends. Journal of Physical Activity and Health. 2012; 9: 129-137.

13. Martinez-Gomez D., Welk G.J., Calle M.E., Marcos A., Veiga O.L. Preliminary evidence of physical activity levels measured by accelerometer in Spanish adolescents: The AFINOS Study. Nutrition Hospitalaria. 2009; 24: 226-232.

14. Aleksey P. Popovich, Valentina I. Gordievskaya, Tatyana A. Kolomiychuk, Anna V. Shchepanova, Anastasiya N. Kuptsova. Innovative technologies of sports selection and orientation as the basis of elite sport. Pedagogiko-psihologicheskie I medico-biologicheskie problemy fizicheskoj kul'tury I sporta = Russian Journal of Physical Education and Sport. 2019; 14(1): 59-66. DOI: 10.14526/2070-4798-2019-14-1-59-66 [In Russ., In Engl.]

\section{Submitted: 20.02.2020}

\section{Author's information:}

Alexey P. Popovich - Candidate of Pedagogics, Associate Professor, First President of Russia B.N. Yeltsin Federal University, 620002, Russia, Yekaterinburg, Mira str., House 19, e-mail: Alex1957popovich@ mail.ru

Alexander V. Bezukladnov - Senior Lecturer, First President of Russia B.N. Yeltsin Federal University, 620002, Russia, Yekaterinburg, Mira str., House 19, e-mail: Bezal-59@mail.ru 